\title{
O perfil ambiental dos afogamentos no Estado do Tocantins
}

O afogamento é um fenômeno em ambiente aquático o qual pode resultar em morte, e no Brasil o Estado do Tocantins apresenta o terceiro índice crescente de óbitos por 100.000 habitantes, com uma média anual em torno de 64 óbitos por afogamento, dos quais $85,29 \%$ ocorrem em rios e/ou represas. Este Estado possui comunidades ribeirinhas e grande potencial turístico, com destaque ao período de veraneio, quando as praias de água doce se tornam ambientes para práticas de lazer e esportes aquáticos. Para este estudo se objetiva investigar qual o perfil ambiental entre os diferentes espaços nos quais se registram os índices de afogamentos no Estado do Tocantins, cujas trilhas metodológicas são compostas por uma pesquisa descritiva, com procedimentos de coleta e fontes de informações em nível de pesquisa bibliográfica e análise documental, método dedutivo e caráter quali-quantitativo. Os principais autores elencados para esta pesquisa foram Silva (2016), Szpilman (2012a; 2012b; 2018), e Silva et al. (2019). Ao final da pesquisa o resultado foi classificado com total, uma vez que houve a discussão do fenômeno afogamento em uma abordagem macro-micro, o apontamento das práticas preventivas diante dos quantitativos referentes aos afogamentos no Estado do Tocantins, e, a correlação das variáveis ambientais com os pontos de afogamentos registrados.

Palavras-chave: Afogamento; Ambiental; Variáveis; Prevenção.

\section{The environmental profile of drowning in the Tocantins State}

The drowning is a phenomenon in aquatic place which can result in death and in Brazil the Tocantins State shows the third growing index deaths per 100,000 inhabitants, with an annual average of around 64 drowning deaths, of wich 85,29\% occur in rivers and/or dams. This state has Riverside communities and great tourist potencial with emphasis on the summering period, when the freshwater beaches become places for leisure and water sports. For this study aims investiagte he environmental profile between the different spaces in which record the drowning rates in Tocantins State, whose methodological trails are composse by descriptive research, with collect procedures and information sources at the level of bibliographic research and document analysis, deductive method and qualiquantitative character. The main authors listed for this research were Silva (2016), Szpilman (2012a; 2012b; 2018), and Silva et al. (2019). At the end of research the result as classified as final, oncethere was the discussion about drowning phenomenon in a macro-micro approach, the note of preventive practices in view of the quantitative referring to drowning in Tocantins State, and, the correlation of environmental variables with the registered drowning points.

Keywords: Drowning; Environmental; Variables; Prevention

Topic: Ciências Sociais e Humanas em Saúde

Reviewed anonymously in the process of blind peer.
Received: 12/04/2020

Approved: 24/08/2020
Cléber José Borges Sobrinho (iD

Universidade Federal do Tocantins, Brasil

http://lattes.cnpq.br/2925929082473530

http://orcid.org/0000-0001-7356-9116

cleberborgess@yahoo.com.br

Claison Alencar Pereira (it)

Corpo de Bombeiros Militar de Goiás, Brasi

http://lattes.cnpq.br/9853256509798284

http://orcid.org/0000-0002-3527-3426

claisonalencar@hotmail.com
Referencing this:

BORGES SOBRINHO, C. J.; PEREIRA, C. A.. O perfil ambiental dos afogamentos no Estado do Tocantins. Health of Humans, v.2, n.2, p.819, 2020. DOI: http://doi.org/10.6008/CBPC2674-6506.2020.002.0002 


\section{INTRODUÇÃO}

O afogamento é um fenômeno id quod causam vinculado à morte, com registro de ocorrência em nível mundial, e, além do perfil comportamental do afogado há outras variáveis que podem influenciar neste resultado fatal, dentre as quais se destaca o espaço ambiental de um afogamento, por meio do qual se pode compreender uma das etapas deste processo.

Este fenômeno aquático é uma causa mortis no mundo, e no período de 2008 a 2011 os gastos públicos com mortes por afogamento no Brasil alcançaram uma média anual de $\mathrm{R} \$ 1,2$ bilhões. Quando se delimita o recorte territorial para a região norte brasileira e o relaciona à variável etária, o resultado é a maior concentração proporcional de afogamentos de crianças em todo o Brasil (SOBRASA, 2018; STOCK, 2018).

Em um comparativo macro-micro, quanto aos óbitos por afogamentos em rios e/ou represas, o Brasil registra 75\% enquanto no Estado do Tocantins esse índice se eleva para 85,29\%; neste Estado o afogamento é classificado como uma ocorrência evitável evolutiva e seu registro consta como nono no ranking nacional em mortes por afogamento a uma média anual em cerca de 64 óbitos por afogamento (SILVA, 2016; BORGES SOBRINHO et al., 2017; SOBRASA, 2018).

Vale destacar que o Tocantins se localiza na região norte brasileira e seu território se situa no centro geodésico, e por este motivo concentra hidrografias fluviais vastas, a exemplo da maior bacia hidrográfica brasileira: a Araguaia-Tocantins, formada por 30 bacias, sendo a Bacia do Araguaia delimitada na porção oeste, com 16 bacias e um terço do volume da água, e, a Bacia do Tocantins delimitada na porção centroleste, com 14 bacias e dois terços de todo volume de água do estado (TOCANTINS, 2015).

Esta grande oferta de águas proporciona a existência de comunidades ribeirinhas e elevada frequência turística, com destaque no período de veraneio, quando da estiagem, que faz com que as águas baixem e apareçam inúmeros bancos de areias, os quais formam as praias de água doce. Estas praias vinculam a dicotomia bem-estar e riscos, pois ao mesmo tempo em que as práticas de lazer e esportes aquáticos são rotineiras, há também os danos ao patrimônio ambiental, ataques de animais aquáticos e afogamentos (TOCANTINS, 2012; OLIVEIRA, 2019).

Nesta compreensão, os afogamentos afetam a população de modo multidisciplinar, nos quesitos educacional, social, financeiro, cultural e econômico, o que transcreve a justificativa necessária à esta pesquisa, uma vez que a compreensão do fenômeno do perfil ambiental dos afogamentos no Estado do Tocantins possibilitará gestão e estratégias para as práticas preventivas aos afogamentos.

Diante do exposto, esta pesquisa tem por objetivo investigar qual o perfil ambiental entre os diferentes espaços nos quais se registram os índices de afogamentos no Estado do Tocantins, e para alcançar tal propósito, haverá a seguinte abordagem tríplice: discutir o fenômeno afogamento em uma abordagem de recorte macro-micro, apontar as práticas preventivas diante dos quantitativos referentes aos afogamentos Estado do Tocantins, e, correlacionar as variáveis ambientais e as características dos pontos de afogamentos registrados. 


\section{REVISÃO TEÓRICA}

\section{O afogamento na concepção nacional macro-micro}

A terminologia Afogamento recebe diferentes conceituações em nível de discussão internacional, e no Brasil se adota o apontamento discursivo de Szpilman (2012a), o qual o define como a "a aspiração de líquido não corporal causado por imersão ou submersão das vias aéreas, e, este fenômeno não deve ser confundido com 'engolir água'”.

Segundo Szpilman (2012b), os principais riscos de afogamento associados as vítimas potenciais são: faixa etária, uso de bebida alcóolica, baixa renda, nível de escolaridade, etnia rural, comportamento de risco, ausência de supervisão, e, doenças prévias, com destaque para as epilepsias, que tornam a vítima em potencial 15 a 19 vezes mais propensa ao afogamento quando em contato com o ambiente aquático.

Segundo o perfil do afogado brasileiro, na concepção de Szpilman (2018), os homens morrem 6,8 vezes mais que as mulheres, com $47 \%$ dos óbitos até os 29 anos sendo a faixa etária crítica entre 15 a 19 anos; das incidências no verão resultam em $44 \%$, sendo que mais de $65 \%$ dos afogamentos acontecem em finais de semana e feriados, e, mais de $50 \%$ ocorrem entre as 10 e 14 horas.

\begin{tabular}{|c|c|c|}
\hline \multicolumn{3}{|c|}{$\begin{array}{l}\text { Estados do Brasil - Óbitos/100.000 } \\
\text { Habitantes - Avaliaçăo de } 19 \text { anos } \\
\qquad(1998-2005 \text { vs 2006-2016) }\end{array}$} \\
\hline & $\begin{array}{l}\text { \% Reduçăo, } \\
\text { Inaiterado ou } \\
\text { aumento }\end{array}$ & $\begin{array}{c}\text { Mortalidade } \\
\left({ }^{*}\right)\end{array}$ \\
\hline Brasil & $-17,98$ & Redução \\
\hline$A C$ & $-6,57$ & Inalterado \\
\hline $\mathrm{AL}$ & $-7,52$ & Inalterado \\
\hline AP & $-4,01$ & Inalterado \\
\hline AM & 12,51 & Aumento \\
\hline BA & 1,35 & Inalterado \\
\hline $\mathrm{CE}$ & $-11,55$ & Redução \\
\hline DF & $-33,26$ & Reduçăo \\
\hline ES & $-22,06$ & Redução \\
\hline GO & $-25,12$ & Redução \\
\hline MA & 46,49 & Aumento \\
\hline MT & $-21,68$ & Redução \\
\hline MS & $-26,51$ & Reduçăo \\
\hline MG & $-14,21$ & Reduçăo \\
\hline PA & 34,86 & Aumento \\
\hline PB & 3,98 & Inalterado \\
\hline PR & $-29,01$ & Reduçăo \\
\hline PE & $-28,34$ & Reduçăo \\
\hline PI & 9,64 & Inalterado \\
\hline RJ & $-33,06$ & Reduçào \\
\hline RN & $-16,27$ & Redução \\
\hline RS & $-30,17$ & Redução \\
\hline RO & $-24,11$ & Reduçăo \\
\hline $\mathbf{R R}$ & $-35,39$ & Reduçăo \\
\hline SC & $-27,76$ & Redução \\
\hline SP & $-35,99$ & Reduçăo \\
\hline SE & $-16,81$ & Redução \\
\hline TO & 18,52 & Aumento \\
\hline
\end{tabular}

Imagem 1: Comparativo de mortalidade dos estados brasileiros em duplo período. Fonte: SOBRASA (2018).

Desta forma se compreende que a maioria dos afogamentos podem ser evitados por obediência dos banhistas às ações preventivas instaladas nas áreas de banho e o saber-fazer de práticas técnicas de natação e salvamento aquático, logo, as situações de vítima de afogamento, bem como de afogamento seguido de 
óbito, podem ter seus índices minimizados (BORGES SOBRINHO et al., 2017).

O comparativo destes índices, em nível de ranking nacional por estados brasileiros, é apresentado pela imagem abaixo, em referência de variância proporcional à 10\% para mais ou para menos dos valores absolutos, e quando há enquadramento nesta configuração o resultado se qualifica no status 'Inalterado', e para os demais resultados haverá qualificação em 'Redução' ou 'Aumento'.

Em análise a este ranking nacional, o Estado do Tocantins desponta como terceiro índice proporcional crescente de óbitos por afogamento para cada 100.000 habitantes, e segundo SOBRASA (2018), em duplo período comparativo de 1998 a 2005 frente a 2006 a 2016, com aumento de 18,52\% o que configura a necessidade de melhor compreensão do fenômeno afogamento, e em consequência uma tentativa de minimização dos índices.

Segundo Silva (2016), um fator a considerar e que o Estado do Tocantins possui características hidrográficas favoráveis ao afogamento, pois além das grande Bacia Hidrográfica do Araguaia-Tocantins, o período de veraneio atrai milhares de turistas a diversos pontos de banho como cachoeiras, represas, balneários e praias particulares.

Tais variáveis são melhor compreendidas segundo o gráfico abaixo:

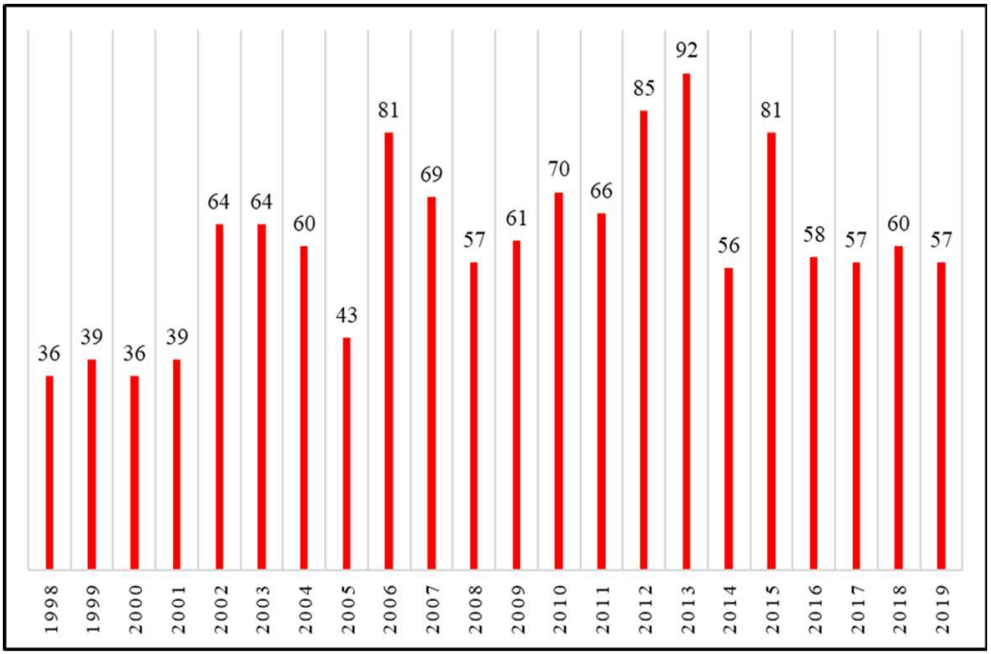

Gráfico 1: Série histórica dos registro de óbitos por afogamentos no Estado do Tocantins. Fonte: Silva (2016).

Neste gráfico se observa que em números reais o ano de 2013 é o ápice de óbitos, o qual é precedido do segundo lugar e seguido do menor índice em um intervalo de 14 anos, contudo, em 2015 há nova crescente com alcance do terceiro maior índice. Logo, o quadriênio 2012-2015 é o espaço temporal crítico, e o quadriênio posterior, 2016-2019, destaca queda numérica seguida de média comportamental.

De posse das teorias e índices supracitados, estabelece-se para a próxima etapa desta pesquisa os apontamentos de quais são as práticas preventivas que ocorrem no Estado do Tocantins a partir do ano de 2017, pois as mesmas incidirão sobre os índices posteriores à série histórica apontada pela SOBRASA.

\section{Práticas preventivas aos afogamentos no Tocantins}

A partir da premissa técnica que o 'acidente acontece onde a prevenção falha', alguns autores ratificam que a prevenção é uma ferramenta eficaz no enfrentamento aos afogamentos, ainda mais quando 
o público-alvo são crianças e adolescentes das regiões ribeirinhas, as maiores vítimas proporcionais brasileiras.

Em complemento, Szpilman (2012b) afirma que as práticas preventivas são as maiores medidas para contribuição na redução dos índices brasileiros aos afogamentos, e que o investimento nesta abordagem proporcionou uma redução de registros em cerca de $39 \%$ nos últimos 34 anos, e que este índice pode ser ainda mais positivo.

As práticas preventivas ao fenômeno afogamento vinculam tanto os fatores populacionais como os fatores externos, ambos em nível de cenário ${ }^{1}$, uma vez que os banhistas e usuários são vítimas em potencial neste ambiente de lazer, cujos agravantes estão nas condutas humanas e no espaço ambiental (BATISTA, 2018; SOBRASA, 2018).

Portanto, conhecer o espaço ambiental possibilita investir tempo e recursos nas abordagens educativas, por meio de: instruções nas salas de aulas a partir da idade escolar infantil; na formação de guarda-vidas; na instalação de placas, bandeiras e boias em ambientes aquáticos de lazer; e, na promoção

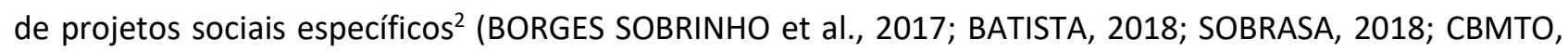
2019c).

No Tocantins, o Corpo de Bombeiros Militar - CBMTO, é o órgão público responsável pelo estudo e aplicação das práticas preventivas aos afogamentos, as quais são compostas pela classificação das praias segundo os níveis de risco, formação de guarda-vidas, realização de convênios com as prefeituras municipais, proposição de normativas para segurança aos banhistas e usuários nos ambientes aquáticos, atuação estacionária e móvel, distribuição de cartilhas ilustrativas, disponibilização de spot ${ }^{3}$ para sonorização e cessão de material arte visual em mídia digital para confecção e instalação de placas, bandeiras e boias (CBMTO, 2019a, 2019b, 2019c).

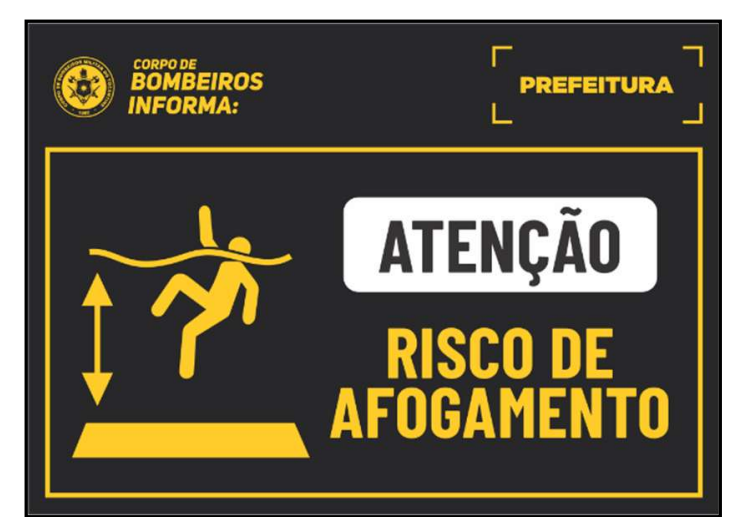

Figura 1: Placa B1. Fonte: CBMTO (2019c

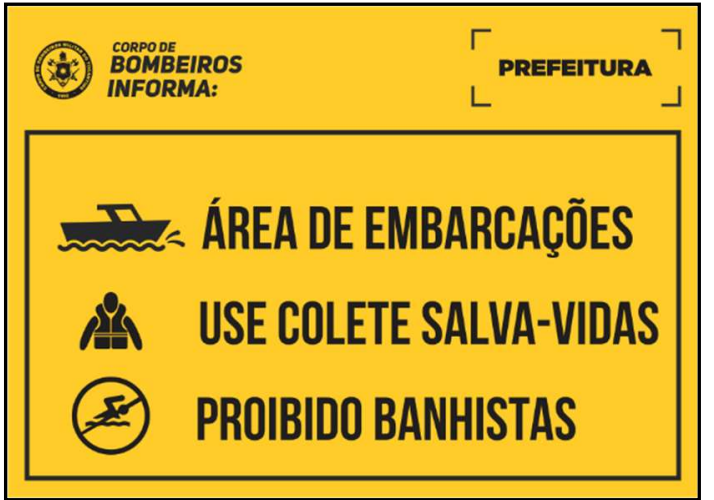

Figura 2: Placa A5. Fonte: CBMTO (2019c).

\footnotetext{
${ }^{1}$ Refere-se às particularidades de cada praia, balneário ou acampamento (BATISTA, 2018).

2 Exemplifica-se nesta pesquisa os projetos Golfinho em Santa Catarina <https://www.ssp.sc.gov.br/index.php/programas/projeto-golfinho> e Botinho no Rio de Janeiro <http://www.cbmerj.rj.gov.br/institucional/item/1715-corpo-de-bombeiros-do-rio-abre-inscricoes-para-o-projetobotinho-2020-na-proxima-segunda-feira-13-01> .

${ }^{3}$ Refere-se a um fonograma disponibilizado às prefeituras para orientar banhistas e usuários dos ambientes aquáticos sobre os cuidados e condutas a serem tomados no respectivo espaço ambiental.
} 


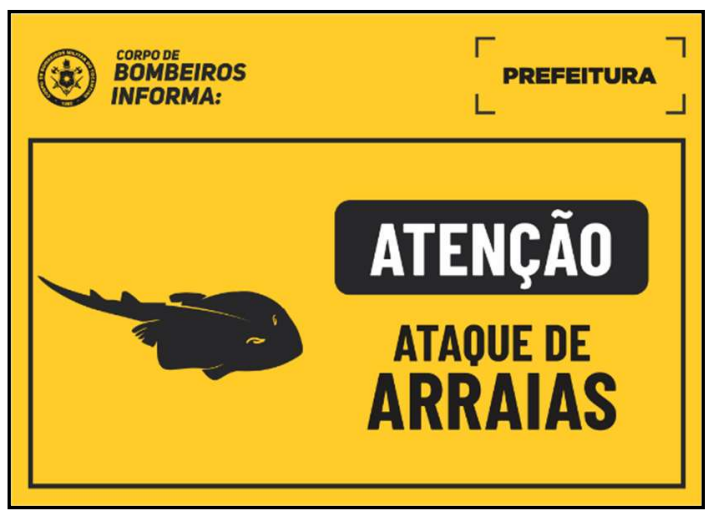

Figura 3: Placa B5. Fonte: CBMTO (2019c).

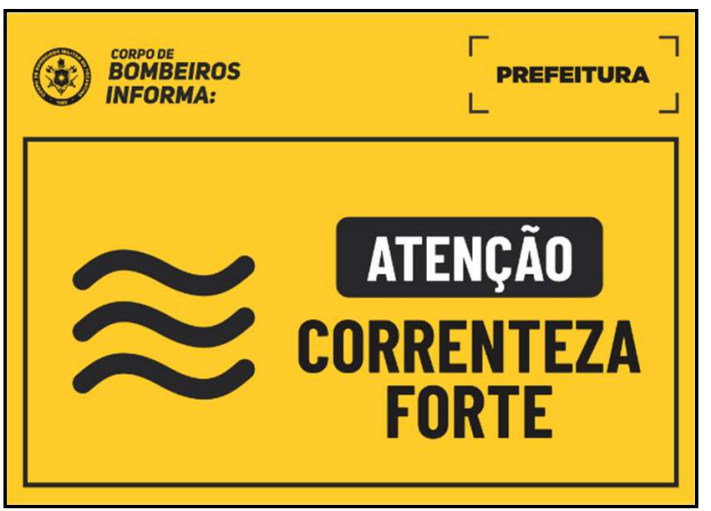

Figura 4: Placa B7. Fonte: CBMTO (2019c).

Destaca-se ainda, conforme disposto por CBMTO (2019c) a modelagem dos dispositivos de segurança, que são as bandeiras e as boias. As bandeiras têm como público-alvo os banhistas e são aplicadas são nas seguintes cores: verde, para baixo risco e supervisão constante; amarela, para médio risco e supervisão periódica; e, vermelha, para alto risco e supervisão eventual. Já as boias são para os condutores e usuários de embarcações e apresentam quatro cores: amarela para delimitação da área aquática de banhistas; vermelha, para formação de área proibida ao tráfego de embarcações e com possibilidade de presença dos banhistas; preta, que indica presença de riscos diversos e/ou delimita uma área de altíssimo risco, proibida ao tráfego de embarcações; e, branco alternado com vermelho, que se refere a uma área de baixo risco para embarcações, proibida ao banho e usada como atracadouro de embarcações comerciais.

O modelo de disposição que o CBMTO indica aos gestores municipais para identificação visual e delimitação das áreas é apresentado a seguir:

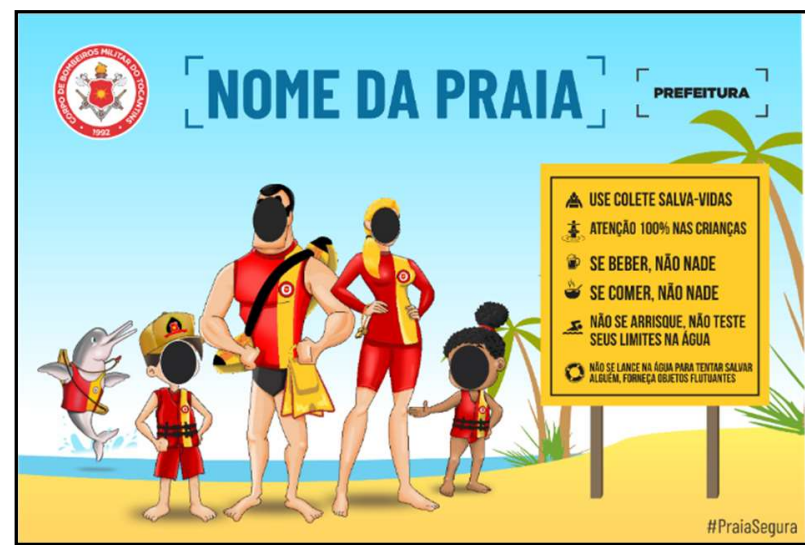

Figura 4: Banner preventivo-interativo. Fonte: CBMTO (2019c).

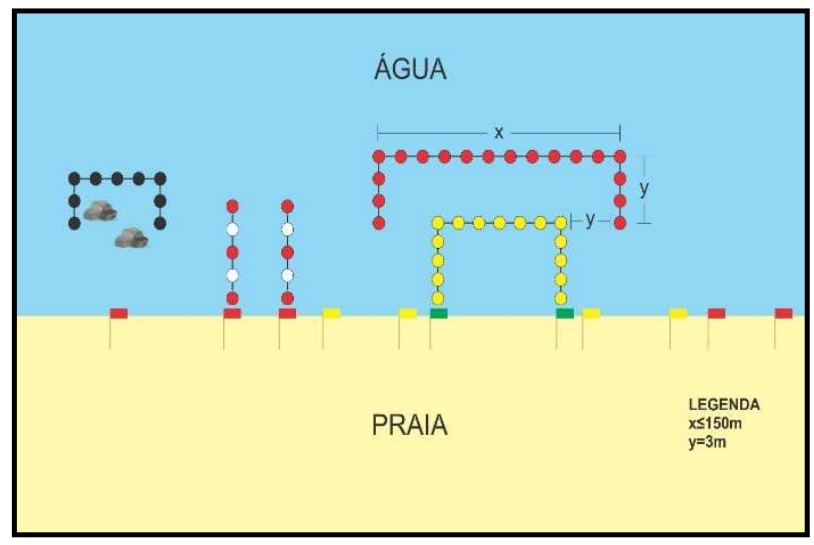

Imagem 2: Disposto exemplar do CBMTO para segurança nas praias. Fonte: CBMTO (2019c).

Portanto, o ambiente aquático para o uso dos banhistas e dos condutores de embarcação com seus respectivos tripulantes deve possuir instrumentos preventivos estacionários a fim de padronizar os pontos de segurança e as áreas de riscos que constam no espaço ambiental destinado ao lazer. Logo, resta correlacionar as variáveis ambientais e as características dos pontos dos afogamentos registrados, o que será apresentado no capítulo de Resultados e Discussão. 


\section{METODOLOGIA}

Esta pesquisa está subsidiada por produções científicas interdisciplinares e arcabouços documentais que referenciem as temáticas do afogamento por meio de abordagens qualitativas para as discussões teóricas, e, abordagens quantitativas para compreensão das principais variáveis ambientais relacionadas aos pontos de afogamento.

Em conformidade à cosmovisão de Creswell (2010), este estudo se configura como caráter qualiquantitativo, pois possibilita estratégias de investigação e compreensões multidisciplinares, por causa das diferentes tipologias associadas, uma vez que há pesquisa bibliográfica e análise documental para subsídio do caráter qualitativo, assim como o levantamento em gráficos para o caráter quantitativo.

Quanto ao objetivo e à justificativa que subsidiam esta pesquisa, há presença do caráter explicativo por se tratar da análise entre a relação dos afogamentos no Estado do Tocantins frente a seu perfil ambiental, a partir da apresentação dos quantitativo de óbitos por 100.000 habitantes em duplo período comparativo na série histórica de 1998 a 2005 frente a 2006 a 2016. Segundo Andrade (2002), a pesquisa explicativa é uma das mais complexas, em virtude da necessidade de registros, análises, classificações e interpretações dos fenômenos estudados pelo pesquisador.

Quanto às fontes de informação, esta pesquisa contém referenciais bibliográficos que fundamentam a discussão teórica associada, que somadas às análises documentais correspondentes visam validar a legalidade e o registro analítico; aponta-se ainda que a investigação qualitativa consiste em “práticas teóricas e estruturas interpretativas" as quais subsidiam a análise dedutiva diante de uma investigação quantitativa, baseada em variáveis estatísticas, o que eleva a possibilidade de rejeitar a subjetividade e validar as variáveis selecionadas (CRESWELL, 2014; LEMOS et al., 2015; SEVERINO, 2017).

Em aplicação à esta pesquisa, a metodologia selecionada possibilitou a discussão dos afogamentos em âmbito nacional sob uma concepção macro-micro, ao que se definiu como recorte territorial o Estado do Tocantins, com o terceiro maior índice comparativo da série histórica registrada, em seguida, apontou as práticas preventivas aos afogamentos desenvolvidas pelo Corpo de Bombeiros Militar do Tocantins.

A próxima ação será correlacionar as principais variáveis ambientais e as características dos pontos de afogamentos registrados em todo território tocantinense por meio dos resultados alcançados com a pesquisa das fichas de ocorrências do CBMTO sobre os óbitos por afogamento referentes ao biênio 20182019, quando iniciou a sistematização dos dados referenciados. Nesta concepção, se tornará possível investigar qual o perfil ambiental entre os diferentes espaços nos quais se registram os índices de afogamentos no Estado do Tocantins.

\section{RESULTADOS E DISCUSSÃO}

As variáveis ambientais de um determinado território são aquelas "realmente pertinentes" à compreensão do espaço e/ou do fenômeno em análise, e as características determinadas estabelecem o grau de impacto e relevância para cada foco a ser reconhecido e discutido (VASCONCELLOS FILHO, 1979). 
Para o estudo dos afogamentos no território tocantinense foram elencadas as seguintes variáveis ambientais: correnteza, tráfego de embarcações, extensão da praia, ataques de animais aquáticos, pedras/rochas, profundidade do ponto de afogamento, distância entre a margem e do ponto de afogamento (CBMTO, 2019a).

Segundo Silva et al. (2019), as variáveis ambientais passaram a compor os estudos sobre afogamentos no ano de 2018, e os principais impactos nos afogamentos do Estado do Tocantins são a distância da margem e a profundidade do ponto de afogamento, portanto, correnteza, tráfego de embarcações, extensão da praia, ataques de animais aquáticos, e, pedras/rochas são fatores secundários.

Para aferição numérica dos índices de óbitos por afogamentos que correlacionam o ponto de afogamento quanto à distância da margem e à profundidade, é aplicado como instrumento de coleta pelo CBMTO o "Relatório de afogamento seguido de óbito", que possui a versão impressa para preenchimento em campo e arquivo na unidade militar que atendeu o afogado, e, a versão digital para estatística institucional e distribuição sistêmica quanto à praia. Por haver um documento oficial do CBMTO que possibilita estabelecer uma estatística para as variáveis ambientais, logo, não há necessidade de aplicação de questionário aos guarda-vidas e/ou mergulhadores, bem como entrevistas (CRESWELL, 2010).

As variáveis ambientais primárias são obtidas mediante a indicação do ponto de afogamento por parte de pelo menos uma testemunha do fenômeno, portanto, não é possível listar com exatidão a distância da margem e a profundidade em todas as ocorrências registradas, uma vez que quando a equipe de bombeiros militares chega no respectivo ponto de afogamento testemunha pode não estar mais no local, com o agravante temporal quando em locais de pontos turísticos e em períodos de temporadas de praia.

Dentre os índices obtidos no biênio 2018-2019, que resultam em uma população real de 117 a variável de distância da margem ao ponto de afogamento compreende uma amostragem de 57,27\%, e sua percepção visual é exibida no gráfico abaixo:

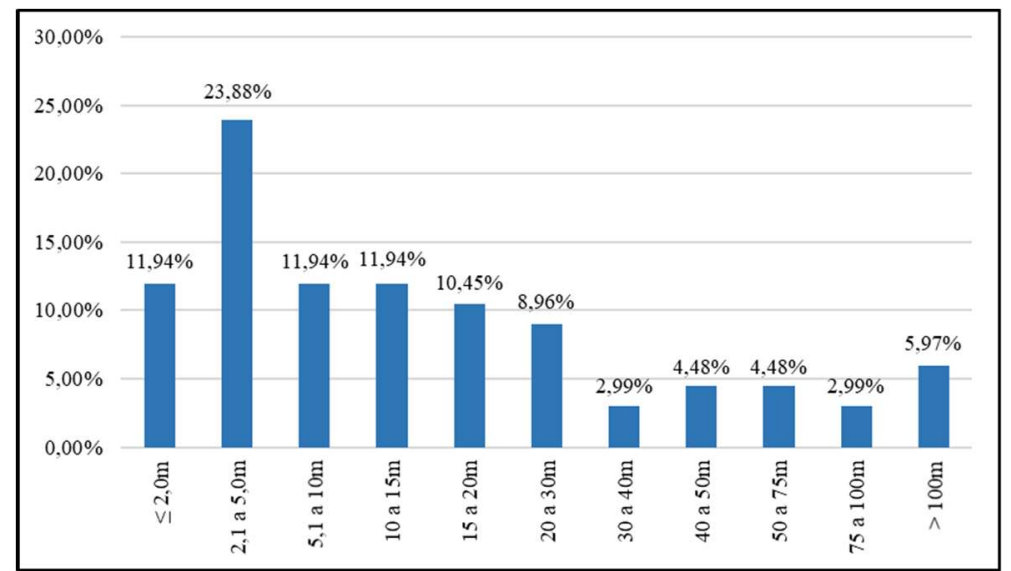

Gráfico 2: Distância entre a margem e o ponto de afogamento. Fonte: Silva et al. (2019).

Compreende-se que dentre os pontos de afogamentos no Estado do Tocantins há concentração focal em uma zona de distanciamento entre dois a cinco metros da margem, em 23,88\% dos afogamentos, e a concentração distributiva, com 59,70\%, em uma zona que inicia na margem e alcança distância limite de quinze metros. 
Quanto à variável ambiental de profundidade, a população real permanece em 117 por também se tratar do biênio 2018-2019, e com amostragem semelhante, a 58,97\%, cujo gráfico abaixo exibe a correspondência:

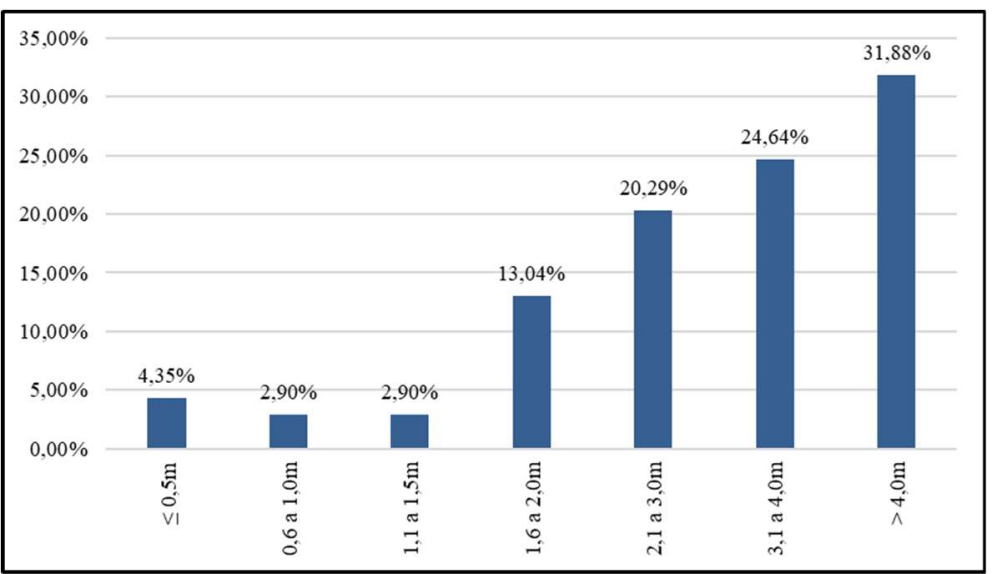

Gráfico 3: Profundidade do ponto de afogamento. Fonte: Silva et al. (2019).

Nesta segunda variável ambiental, observa-se que os afogamentos no Estado do Tocantins possuem concentração focal em uma zona de profundidade igual ou superior a quatro metros, EM $31,88 \%$ dos afogamentos, e concentração distributiva, com $56,52 \%$, em pontos de afogamentos a partir de três metros de profundidade.

Desta forma, verifica-se que as variáveis ambientais primárias apontam que os pontos de afogamento no Estado do Tocantins estão concentrados em ambientes aquáticos situados em uma zona de até quinze metros da margem e com profundidade a partir de três metros. Contudo ainda resta conhecer as características destes pontos de afogamentos registrados para ser possível estabelecer uma correlação.

Diante desta necessidade foi elaborado em 23 de abril de 2020 o mapeamento das praias, balneários e dos eventos temporários referentes ao veraneio tocantinense, em uso ao software Google Maps com dados de acesso restrito aos gestores do processo, por meio do qual aponta o município, o nome da praia, o nível de risco, as varáveis ambientais, estimativa de público nos horários de pico, o quantitativo de GV e GVC previsto, suporte de saúde municipal, se está regularizada em nível de serviços técnicos, as coordenadas geográficas e uma imagem do local.

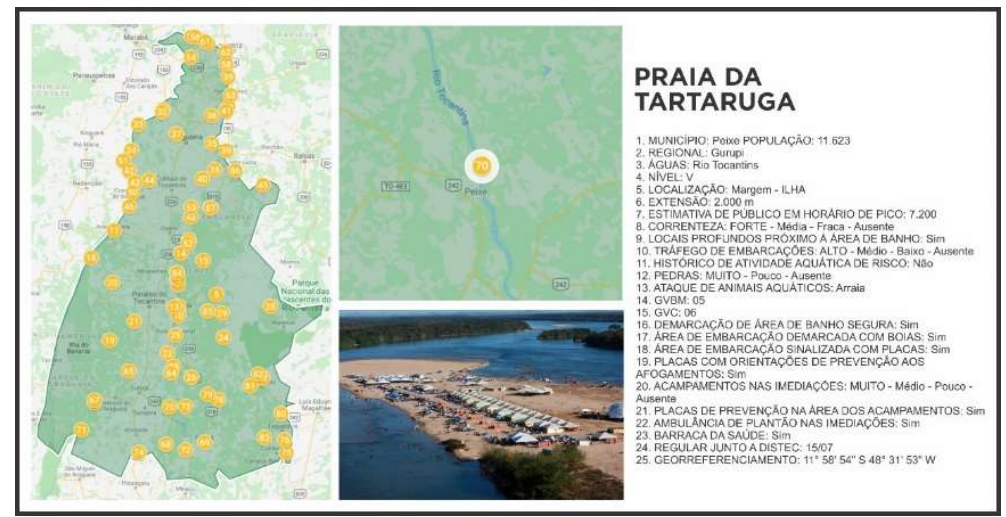

Imagem 3: Mosaico macro-micro - “Praias TO 2019”. Fonte: Silva (2020a).

Portanto, o mosaico acima apresenta a sequência de aplicação de software livre com acesso ao 
'Praias TO 2019', com posterior escolha da Praia da Tartaruga localizada no município tocantinense de Peixe, com informação disponível da localização e o tempo médio de deslocamento via automóvel; ao clicar na opção 'Rotas' se permite conhecer os possíveis caminhos com quilometragem de distância, e, ao clicar na opção 'Mais Informações' serão disponibilizadas 25 variáveis e uma foto do local.

Nesta mesma compreensão foi também criado o mapa 'Afogamentos Fatais 2019' com o registro dos 57 pontos de afogamentos do ano em referência. A saber:

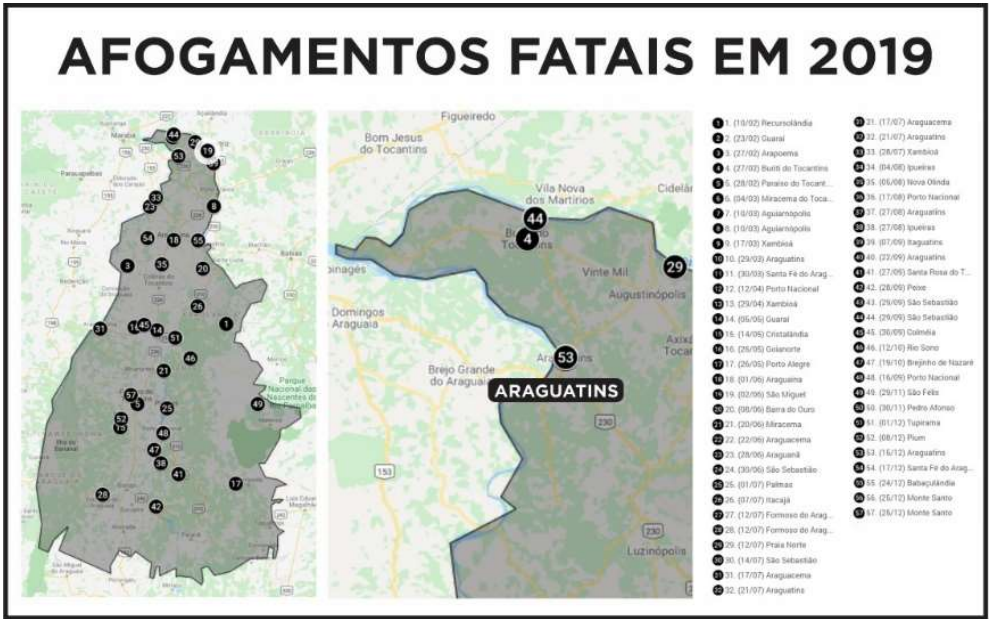

Imagem 4: Mosaico macro-micro - “Afogamentos Fatais 2019”. Fonte: Silva (2020b).

Por meio o aplicativo Google Maps se estabeleceu os pontos de afogamentos no Estado do Tocantins para o ano de 2019, e quando o usuário clicar em qualquer círculo numerado abrirá uma tela que identificará o município do afogamento e uma lista com cada ponto de afogamento registrado e sua ordem cronológica com a respectiva data do afogamento referenciado.

Por exemplo, ao clicar no círculo de número 53, que simboliza o quinquagésimo terceiro afogamento registrado no ano de 2019, identifica-se que ocorreu no município de Araguatins, contudo há um segundo número divergente caracterizando o município, número '10', e com a data de '29/03', o que significa que neste município houve mais de um afogamento registrado. E ao clicar na opção 'Mais Informações' o usuário terá acesso a quais municípios e em que data houve o afogamento associado, e ainda com possibilidade de compartilhamento destas informações.

Diante do exposto, houve correlação das variáveis ambientais com as características dos pontos de afogamentos, uma vez que os bombeiros militares se fizeram presentes em atuações operacionais de guardavidas e/ou mergulhadores, o que culminou na identificação das variáveis ambientais, e, somado à aplicação de tecnologia se tornou possível registrar e conhecer os pontos de afogamentos do Estado do Tocantins.

\section{CONCLUSÕES}

O afogamento é um fenômeno em ambiente aquático o qual pode resultar em morte e já acarretou um prejuízo financeiro em média de $\mathrm{R} \$$ 1,2 bilhões no Brasil, território no qual três dos quatro índices crescentes da série histórica para 100.000 habitantes estão localizados na região norte, e, o recorte para esta pesquisa foi o Estado do Tocantins, com uma média anual em torno de 64 óbitos por afogamento, dos quais 


\section{$85,29 \%$ ocorrem em rios e/ou represas.}

O Estado do Tocantins concentra riquezas fluviais e possui a maior bacia hidrográfica brasileira, o que resulta em inúmeras opções de praias, balneários, cachoeiras, represas, competições esportivas e eventos turísticos, com destaque ao período de veraneio, quando há o aparecimento das praias de água doce em virtude da estiagem.

A população tocantinense é impactada pelos afogamentos em aspectos multidisciplinares, nas áreas educacional, social, financeira, cultural e econômica, logo, verifica-se a necessidade de melhor conhecer o fenômeno para estabelecer práticas preventivas às condutas humanas e em aproveitamento ao espaço ambiental, a fim de reduzir os índices destes afogamentos.

O órgão público tocantinense responsável pelos estudos e enfrentamento aos afogamentos é o СВMTO, que por meio de subsídios legais dispõe de práticas preventivas para classificação das praias segundo seus níveis de risco, formação de guarda-vidas militares e civis, realização de convênios com as prefeituras, normatização para segurança de banhistas e usuários dos ambientes aquáticos diversos, entre outras ações que considerem as variáveis ambientais e os pontos de afogamento.

As variáveis ambientais elencadas para este estudo foram distribuídas em primárias e secundárias, sendo que as principais foram a distância entre a margem e o ponto de afogamento, e, a profundidade do ponto de afogamento; enquanto as secundárias, as quais não são pormenorizadas nesta pesquisa, foram a correnteza, as pedras/rochas, o tráfego de embarcações, a extensão da praia, e, os ataques de animais aquáticos.

Estas variáveis ambientais são obtidas quando em atendimento à situação emergencial de afogamento seguido de óbito, mediante o apontamento do ponto de afogamento por testemunhas, logo, a tendência é que a população de afogados não será idêntica à amostragem, como de fato assim o foi nesta pesquisa. Contudo, destaca-se que a coleta das variáveis ambientais iniciou no ano de 2018 , e os índices comparativos pertencem ao biênio 2018-2019, os quais resultam em uma população real de 117 óbitos por afogamento, com a variável de distância da margem ao ponto de afogamento a uma amostragem de 57,27\%, e, a variável de profundidade do ponto de afogamento a uma amostragem semelhante de $58,97 \%$. Desta forma, foi possível verificar que os pontos de afogamentos no Estado do Tocantins estão concentrados em ambientes aquáticos situados em uma zona de até quinze metros da margem e com profundidade a partir de três metros.

Para estabelecer uma correlação destas variáveis ambientais com os pontos de afogamento, foi criado por meio do software Google Maps o mapeamento dos espaços ambientais aquáticos referentes ao veraneio tocantinense com informações que subsidiam a atuação operacional dos guarda-vidas e dos mergulhadores, assim como o mapeamento dos pontos de afogamento por ordem cronológica e com a respectiva data do afogamento referenciado.

Ao final desta pesquisa o resultado foi classificado com total, uma vez que houve a discussão do fenômeno afogamento em uma abordagem macro-micro, o apontamento das práticas preventivas diante dos quantitativos referentes aos afogamentos Estado do Tocantins, e, a correlação das variáveis ambientais 
com os pontos de afogamentos registrados.

Desta forma, investigou-se qual o perfil ambiental entre os diferentes espaços nos quais se registram os índices de afogamentos no Estado do Tocantins, o que, por meio desta pesquisa, possibilita a contribuição para o planejamento das atividades preventivas associadas e consequente minimização dos índices de afogamentos.

\section{REFERÊNCIAS}

BORGES SOBRINHO, C. J.; BORGES SOBRINHO, O. C. B.. Perspectivas curriculares e princípios andragógicos na formação profissional de bombeiros militares. Revista Flammae, João Pessoa, v.03, n.08, p.519-538, 2017.

CBMTO. Corpo de Bombeiros Militar do Tocantins. Portaria n. 001/2019/COB, de 10 de maio de 2019. Estabelece a classificação e reclassificação das praias e eventos temporários para a Temporada 2019. Diário Oficial do Estado do Tocantins no 5.361, de 21 de maio de 2019. Palmas: CBMTO, 2019a.

CBMTO. Corpo de Bombeiros Militar do Tocantins. Portaria n. 002/2019/COB, de 10 de maio de 2019. Estabelece diretrizes sobre a capacitação de Guarda-Vidas Civis para atuação na temporada de praia sob coordenação do CBMTO. Diário Oficial do Estado do Tocantins № 5.361, de 21 de maio de 2019. Palmas: CBMTO, 2019b.

CBMTO. Corpo de Bombeiros Militar do Tocantins. Portaria n. 004/2019/COB, de 30 de maio de 2019. Atualiza as sinalizações obrigatórias a serem adotadas nas praias do Estado do Tocantins. Diário Oficial do Estado do Tocantins № 5.373, de 06 de junho de 2019. Palmas: CBMTO, 2019c.

CRESWELL, J. W.. Projeto de Pesquisa: método qualitativo, quantitativo e misto. 3 ed. Porto Alegre: Artmed, 2010.

CRESWELL, J. W.. Investigação qualitativa e projeto de pesquisa: escolhendo entre cinco abordagens. 3 ed. Porto Alegre: Penso, 2014.

LEMOS, F. C. S.; CRISTINA, F.; GALINDO, D.; REIS JÚNIOR, L. P.; MOREIRA, M. M.; BORGES, A. G.. Análise documental: algumas pistas de pesquisa em psicologia e história. Psicologia em estudo, Maringá, v.20, n.3, p.461-469, 2015.

OLIVEIRA, W.. Licenciamento das parias tocantinenses: situação de registro e regularidade. Listagem em classificação de 101 praias. Palmas: Instituto Natureza do Tocantins, 2019.

SEVERINO, A. J.. Metodologia do trabalho científico. 24 ed. São Paulo: Cortez, 2017.
SILVA, A. L. S.. Perfil do afogamento seguido de óbito no Estado do Tocantins. Monografia (Especialização em Gerenciamento de Segurança Pública) - Universidade Estadual de Goiás, Goiânia, 2016.

SILVA, A. L. S.. Praias TO 2019. Palmas, 2020a.

SILVA, A. L. S.. Afogamentos Fatais 2019. Palmas, 2020b.

SILVA, A. L. S.; BORGES SOBRINHO, C. J.; SILVA, M. G.. Sistema de Prevenção à afogamentos do Estado do Tocantins. In: SEMINÁRIO NACIONAL DE BOMBEIROS SENABOM, 19. Anais. São Luís: SENABOM, 2019.

SOBRASA. Sociedade Brasileira de Salvamento Aquático. Afogamentos: o que está acontecendo? Boletim Brasil 2018. Rio de Janeiro: SOBRASA, 2018.

SZPILMAN, D.. Manual de emergências aquáticas. Versão atualizada em dezembro de 2013. Rio de Janeiro: SOBRASA, 2012a.

SZPILMAN, D.. Afogamento: Perfil epidemiológico no Brasil: Ano 2012. Rio de Janeiro: SOBRASA, 2012b.

SZPILMAN, D.. Afogamento: Perfil epidemiológico no Brasil: Ano 2018. Rio de Janeiro: SOBRASA, 2018.

STOCK, A.. Afogamento e a maior cause de mortes acidentais com crianças no Brasil: saiba como evitar. São Paulo: BBC News, 2018.

TOCANTINS. Atlas do Tocantins: subsídios ao planejamento de gestão territorial. 6 ed. Palmas: Secretaria de Planejamento - SEPLAN, 2012.

TOCANTINS. Bacias Hidrográficas: Araguaia Tocantins. Palmas: Secretaria de Planejamento - SEPLAN, 2015.

VASCONCELLOS FILHO, Paulo de. Análise ambiental para o planejamento estratégico. Revista de Administração de Empresas, Rio de Janeiro, v.19, n.2, p.115-127, 1979.

A CBPC - Companhia Brasileira de Produção Científica (CNPJ: 11.221.422/0001-03) detém os direitos materiais desta publicação. Os direitos referem-se à publicação do trabalho em qualquer parte do mundo, incluindo os direitos às renovações, expansões e disseminações da contribuição, bem como outros direitos subsidiários. Todos os trabalhos publicados eletronicamente poderão posteriormente ser publicados em coletâneas impressas sob coordenação da Sapientiae Publishing, da Companhia Brasileira de Produção Científica e seus parceiros autorizados. Os (as) autores (as) preservam os direitos autorais, mas não têm permissão para a publicação da contribuição em outro meio, impresso ou digital, em português ou em tradução. 